\title{
Structural alterations in hypoxia-sensitive neuronal populations after cardiac arrest in rats of different sex: the relationship with BDNF protein expression
}

Kuzovlev A.N., Ostrova I.V., Avruschenko M.Sh.

V.A. Negovsky Research Institute of General Reanimatology, Federal Research and Clinical Center of Intensive Care Medicine and Rehabilitology, Moscow, Russia

ФНКЦ РР

Purpose of the study: To evaluate an expression level of brain-derived neurotrophic factor (BDNF) in highly sensitive to hypoxia neuronal populations of male and female rats after total ischemia.

Materials and Methods: Cardiac arrest in adult albino male and female rats $(n=25)$ was evoked by intrathoracic clamping of cardiac vascular bundle for $10 \mathrm{~min}$. Sham-operated animals served as control $(n=10)$. Animals were resuscitated with the aid of chest compressions combined with mechanical air ventilation by "Animal Respirator" (SMT Geratehandel) followed by intratrachea administration of $0.1 \mathrm{mg} / \mathrm{kg}$ adrenaline solution.

The pyramidal neurons of the hippocampus (field CA4) and Purkinje cells of the cerebellum were analysed on the 1, 4, 7 and 14th day after resuscitation.

The expression of BDNF protein was determined by peroxidase-antiperoxidase method using polyclonal antibodies to BDNF (Santa Cruz, USA) and LSAB TM +Kit visualizing system (DAKO, Denmark).

The intensity of BDNF expression in the neuron's cytoplasm was assessed from the mean optical density using image analysis software ImageJ $1.48 \mathrm{v}$. A number of neurons with different expression level of BDNF as well as a total number of neurons (per $1 \mathrm{~mm}$ of their layer length) were evaluated.

Statistical data processing was performed using Statistica 7.0. The significance of differences was assessed by Student's t-test, Mann-Whitney test, Kolmogorov-Smirnov test.

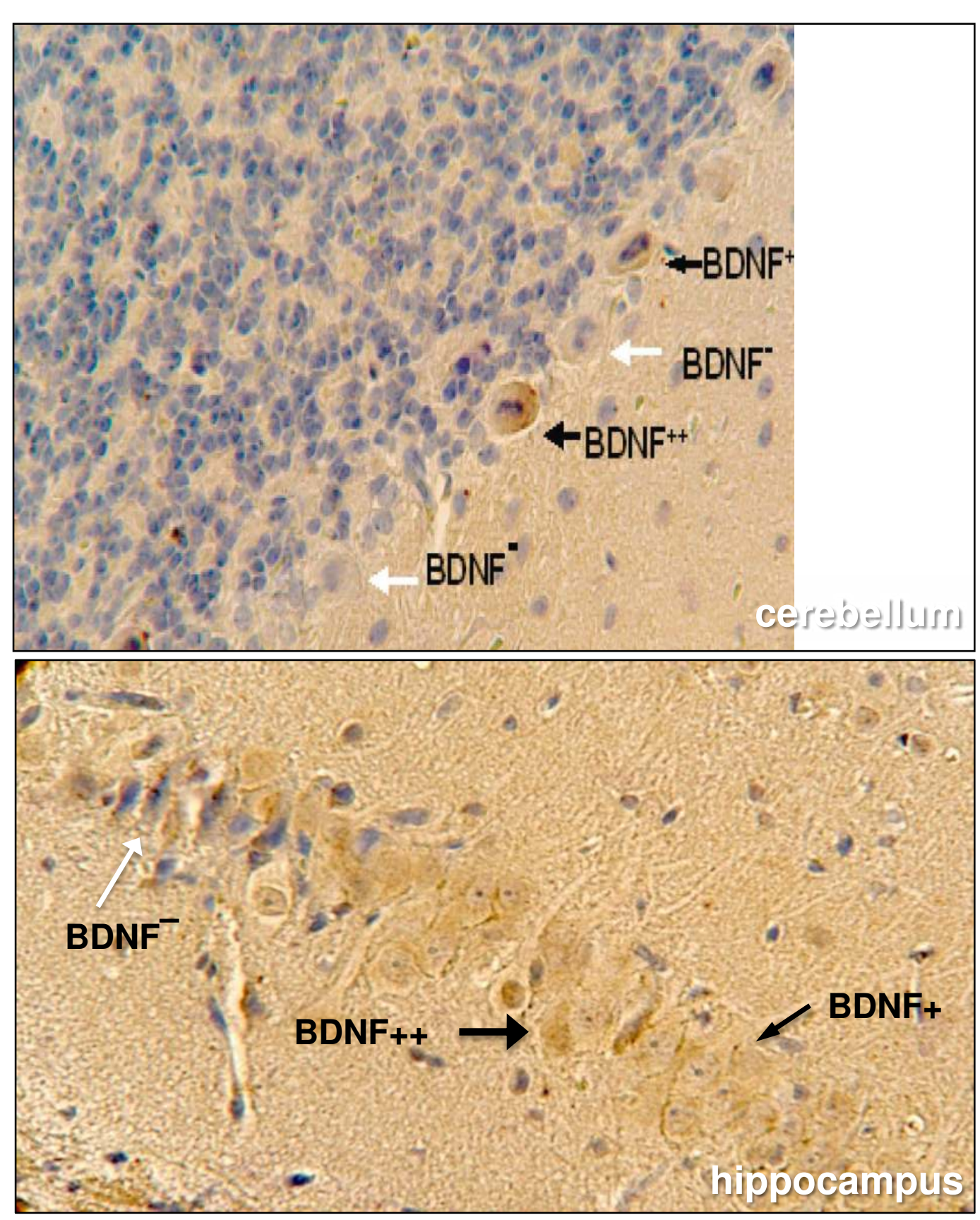

Fig. 1. Neurons with different levels of BDNF expression. Indirect peroxidase-antiperoxidase method, hematoxylin staining, $x 400$. BDNF ${ }^{-}$BDNF-negative cells;

$\mathrm{BDNF}^{+}$- weak-positive cells;

$\mathrm{BDNF}^{++}$- strong-positive cells.

\section{Conclusion:}

- Cardiac arrest causes more pronounced neuronal injury in male rats compared to

female ones as well as shifts in the expression level of BDNF.

- There are interrelation between BDNF expression shifts and the postresuscitative neuronsal loss.

- The high level of BDNF protein enhances sustainability of neurons to ischemiareperfusion.
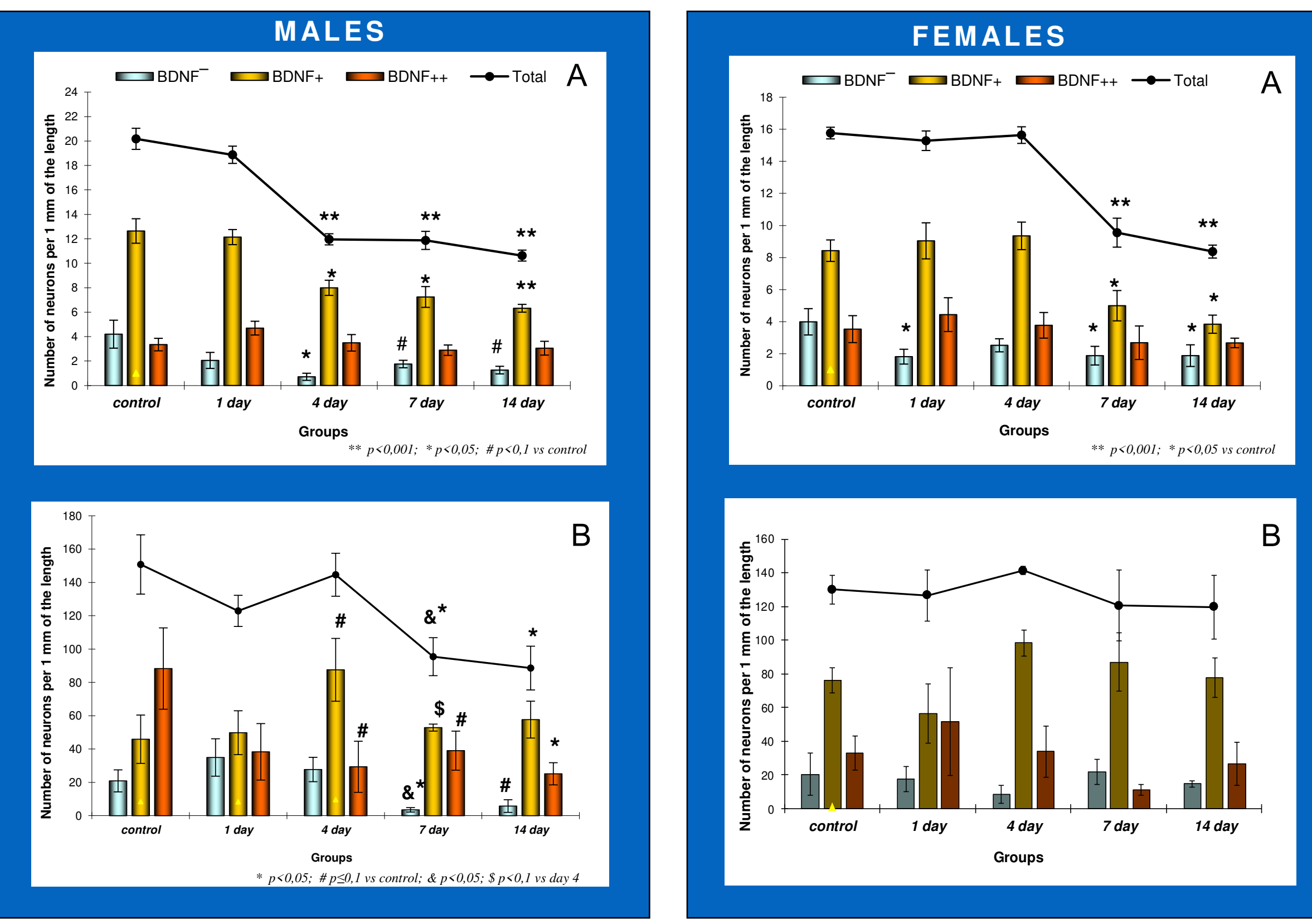

Fig.2. Decrease in the overall density of neurons:

in the cerebellum (A) - in males - by day 4 , in females - by day 7 postresuscitation;

in the hippocampus (B) - in males - by day 7 , in females - no neuronal loss

Table. The level of BDNF protein expression:

\begin{tabular}{|c|c|c|}
\hline & Males & Females \\
\hline The cerebellum & $\begin{array}{c}\text { Decrease by day 4: } \\
\text { BDNF- cells } \downarrow \text {; BDNF }^{+} \text {cells } \downarrow \text {; } \\
\text { BDNF }^{++} \text {no change }\end{array}$ & $\begin{array}{c}\text { Decrease by day } 7 \text { : } \\
\text { BDNF- cells } \downarrow ;^{\text {BDNF }}+\text { cells } \downarrow ; \\
\text { BDNF }^{++} \text {no change }\end{array}$ \\
\hline The hippocampus & $\begin{array}{c}\text { Decrease by day 7: } \\
\text { BDNF- cells } \downarrow \text {; BDNF+ cells } \downarrow \text {; } \\
\text { BDNF++ cells } \downarrow\end{array}$ & No change \\
\hline
\end{tabular}

In both neuronal populations at the stage of neuronal loss only BDNF-negative and BDNF-weak-positive neurons die. 